\title{
Fenomena Penggunaan Bahasa Daerah di Kalangan Remaja
}

\author{
Felta Lafamane \\ feltafamane@gmail.com
}

\begin{abstract}
Abstrak
Bahasa merupakan alat atau perwujudan budaya yang digunakan manusia untu saling berkomunikasi atau berhubungan, baik melalui tulisan, lisan atau kemauan kepada lawan bicaranya (orang lain). melalui bahasa, manusia dapat menyesuaikan diri dengan adat istiadat, tingkah laku, tata karma masyarakat, dan sekaligus untuk membaurkan dirinya dengan segala bentuk masyarakat. Di Indonesia merupakan sebuah negera dengan jumlah penduduk terbesar ke-4 di dunia. Terdapat berbagai macam suku, budaya, bangsa, ras, maupun agama. Dari hal ini pastilah Indonesia juga memiliki beragam bahasa. Terdapat sekitar 724 bahasa daerah yang tersebar di seluruh pelosok negeri ini. Setiap daerah pasti mempunyai keunikan tersendiri terkait bahasa mereka. Misalnya saja dalam bahasa jawa, terdapat berbagai macam tingkatan kebahasaan misalnya kromo dan ngoko. Bahasa kromo digunakan untuk berbicara kepada orang yang lebih tua sedangakan bahasa ngoko digunakan untuk berbicara dengan orang yang seumuran atau dibawahnya. Inilah sebagian contoh kecil dari keunikan yang terdapat dalam bahasa daerah yang tidak terdapat dalam bahasa indonesia. Fenomena yang terjadi sekarang, para remaja yang merupakan salah satu pelaku dalam pemertahanan bahasa daerah sudah jarang menggunakan bahasa daerah. Dalam lingkungan masyarakat kedudukan bahasa daerah mengalami penurunan, hal ini dipengaruhi oleh penggunaan bahasa kedua dan ketiga mereka seperti bahasa indonesia dan bahasa asing. Bagi para remaja bahasa Indonesia dan bahasa Asing memiliki kedudukan yang berprestise atau bergengsi dibanding bahasa Daerah.
\end{abstract}

Keyword: fenomena, fungsi, bahasa daerah, remaja

Abstract

Language is a tool or cultural embodiment used by humans to communicate or relate to each other, whether through writing, oral or willingness to the interlocutor (others). through language, humans can adapt themselves to the customs, behavior, community karma, and at the same time to blend themselves with all forms of society. In Indonesia is a country with the 4th largest population in the world. There are various kinds of ethnicity, culture, nation, race, and religion. From this, surely Indonesia also has a variety of languages. There are around 724 regional languages spread throughout the country. Each region must have its own uniqueness related to their language. For example, in Javanese, there are various levels of language such as kromo and ngoko. The kromo language is used to talk to older people while the ngoko language is used to talk to people of the same age or below. Here are some small examples of the uniqueness found in local languages that are not in Indonesian. The phenomenon that is happening now is that teenagers who are one of the perpetrators of maintaining regional languages rarely use regional languages. In the community environment the position of regional languages has decreased, this is influenced by the use of their second and third languages such as Indonesian and foreign languages. For teenagers, Indonesian and foreign languages have prestigious or prestigious positions compared to Regional languages.

Keyword: phenomena, functions, regional languages, adolescents 


\section{Karakteristik Bahasa Daerah}

Bahasa-bahasa daerah yang ada di Indonesia memiliki ciri dan karakteristik yang berbeda antara satu bahasa dengan bahasa yang lain. Keunikan bahasa setiap daerah menandakan identitas daerah tertentu, sehingga penting untuk dilakukan suatu kajian yang dapat dengan jelas menunjukkan keunikan tersebut. Hal itu perlu menjadi perhatian utama, karena kebanyakan dalam menyebut bahasa yang satu dengan yang lain merupakan bahasa yang berbeda atau hanya perbedaan variasi, belumlah jelas. Masing-masing daerah tidak ingin bahasanya disama-samakan dengan bahasa di daerah yang lain ( $S$, Susiati, 2019). Kekayaan luar biasa yang tanpa kita sadari perlahan lenyap dan punah di negeri ini. Yaitu bahasa daerah. Bahasa daerah adalah kekayaan terakhir sebuah bangsa sebagai bukti adanya peradaban, seni dan budaya bahkan eksistensi bangsa itu sendiri yang diwariskan baik secara lisan maupun tulisan. Kondisi terancamnya bahasa daerah mendorong Badan Unesco PBB menetapkan tanggal 21 Februari sebagai hari bahasa daerah internasional. Menurut data Organisasi Pendidikan, Keilmuan dan Kebudayaan PBB (Unesco: United Nations Education, Social and Culture Organization) pada 2014 menyebutkan bahwa sebanyak 3000 dari 6000 bahasa di dunia hampir punah, sebagian besar milik etnis minoritas (Republika, 24/9/14). Menurut Direktur Unesco Sheldon Shaefffer bahwa 96 persen dari bahasa yang hampir punah (3000 bahasa) itu hanya digunakan oleh 4 persen populasi dunia. Lebih parahnya menurut data dari Ethnologue Languages of the World melaporkan bahwa untuk kawasan Asia Tenggara terdapat 527 bahasa terancam hampir punah. Sedangkan di Indonesia menurut hasil penelitian Lembaga Ilmu Pengetahuan Indonesia (LIPI) bahwa dari 746 bahasa daerah yang ada di tanah air sebanyak 169 bahasa terancam punah dengan kondisi jumlah penutur di bawah 500 orang, sudah tua-tua serta tidak ada generasi muda pengganti dan berada di lokasi terpencil.

\section{Fungsi Bahasa Daerah}

Sebagian besar masyarakat Indonesia menjadikan bahasa daerah sebagai bahasa ibu. Di samping itu ia juga berfungsi sebagai bahasa budaya, bahasa pemersatu intra-etnis, mempererat keakraban serta untuk mengetahui sejarah dan bukti peninggalan nenek moyang dalam bentuk perangkat bertutur. Bahasa daerah memegang peranan penting sebagai indentitas, ciri khas, alat komunikasi, dan instrument selama berabad-abad hingga ribuan tahun lewat lisan dan tulisan.

Beruntung bagi anak yang lahir dari keluarga yang membiasakan berbahasa daerah dalam aktivitas sehari-hari di rumah. Misalnya kedua orantuanya suku Batak Mandailing dan berbicara Bahasa Batak Mandailing dalam keseharian, otomatis anaknya akan lancar, fasih dan paham aturan budaya, adat dan seni dalam suku Mandailing. Begitu pula yang suku Jawa, Melayu, Aceh, Karo dan lain-lain. Ketika si anak tumbuh besar, dia tidak saja menguasai bahasa daerah yang diterimanya di rumah dan lingkungan sosial masyarakat, tetapi juga akan fasih menguasai Bahasa Indonesia sebagai bahasa nasional yang didapat di bangku sekolah TK, SD, SMP, SMA hingga perguruan tinggi. 
Jadi sangat dianjurkan bagi para orangtua untuk membiasakan anak berkomunikasi dengan bahasa daerah. Jangan pernah takut atau khawatir anak akan gagap berbahasa Indonesia gara-gara sejak kecil lebih dibiasakan bahasa daerah, karena lambat laut si anak akan cepat belajar bahasa Indonesia di lingkungan sosial sekolah dan masyarakat. Sangat disayangkan kadangkala ada anak memiliki marga Batak, tetapi tidak bisa bahkan tidak tahu bahasa daerahnya sendiri. Juga ada siswa atau mahasiswa mengaku bersuku Jawa tetapi sama sekali tidak bisa memahami apalagi menuturkan Bahasa Jawa baik Kromo maupun Ngoko. Begitu pula yang Karo, Aceh, Melayu dan lain-lain. Hal ini banyak dijumpai baik di kota maupun di desa. Sudah bisa diprediksi bagaimana generasi selanjutnya ketika si anak menikah dan memiliki anak, otomatis anak keturunannya sehari-hari tidak berkomunikasi dengan bahasa daerah. Lambat laun bahasa daerah pudar, terlupakan, adat istiadat dan budaya dianggap kuno dan dipandang ketinggalan zaman. Tentu, kita tidak ingin hal itu terjadi. Jadi, seorang anak fasih dan lancar berbahasa daerah dan budaya serta adat istiadatnya sangat dipengaruhi lingkungan keluarga (ayah, ibu dan anggota keluarga) dan lingkungan masyarakat.

\section{Fasih Dwi-Bahasa}

Kementerian Pendidikan dan Kebudayaan memang sudah mengintruksikan integrasi bahasa daerah dalam mata pelajaran muatan lokal di sekolah-sekolah. Namun, jika mengandalkan pihak sekolah dalam menjaga kelestarian bahasa daerah maka kecil sekali kemungkinannya membuat siswa fasih, lancar berbahasa daerah dan mengerti seni dan budaya sukunya sendiri. Di samping itu komunitas seni dan budaya yang melestarikan bahasa, budaya, dan bahasa dalam pentas, sastra maupun bentuk lain juga belum cukup bila pengaruh dalam keluarga dan lingkungan sosial masyarakat tidak kuat dalam berbahasa daerah. Meskipun usaha tersebut mulia, namun juga harus bekerjasama dengan orangtua siswa di mana memiliki pengaruh lebih besar dalam pembentukan bahasa daerah si anak dalam hidup sehari-hari.

Banyak contoh bahasa daerah yang musnah akibat tidak dilestarikan. Seperti di Papua bahasa Bonerif, Mafia, Saponi, di Sumatera bahasa Lom, di Sulawesi bahasa Dampal, Bahonsai, Baras dan BudongBudong. Di Kalimantan Bahasa Punan Merah, Lengilu, Kareho Ureng di Maluku Bahasa Hukumina, Nakaela, Hoti Hulung dan lain-lain. Jadi, membiasakan diri kita berbahasa daerah membawa nilai plus. Di samping fasih berbahasa daerah, juga fasih berbahasa Indonesia. Terlebih bila juga menguasai bahasa asing seperti Bahasa Inggris, Arab, Mandarin, Jepang, Prancis dan sebagainya.

Jadi tidak hanya tangkas dan akrab bersosialisasi bersama keluarga besar dan masyarakat sekitar dengan bahasa daerah, tetapi juga fasih berkomunikasi dalam forum resmi di masyarakat, sekolah dan dalam kebutuhan formal dengan bahasa Indonesia. Serta juga aktif dan berpartisipasi dengan Bahasa Inggris. Terpenting adalah tahu di mana tempat dan kondisi dalam mempergunakan bahasa baik bahasa daerah, bahasa nasional Indonesia maupun bahasa asing. Tentunya menguasai bahasa daerah sebagai bentuk menjaga kelestarian kekayaan bahasa daerah di Indonesia. Fenomenanya, penggunaan bahasa daerah sudah mulai luntur, jarang sekali orang tua mengajarkan bahasa daerah kepada anak-anak. Tidak hanya 
pendidikan utama di rumah yang sudah tidak menggunakan bahasa daerah, melainkan di lingkungan pun mulai tergeser. Desa yang kemungkinan menjaga terlestarinya bahasa daerah pun sekarang terjajah dengan pembangunan-pembangunan yang mengarah pada "meng-kota-kan desa ". Lambat laun desa pun berubah menjadi kota dengan cepatnya perkembangan.

Hal ini juga berpengaruh dalam penggunaan bahasa yang menjadi peran penting dalam komunikasi. Dan ini tentu mempengaruhi fungsi bahasa; fungsi edukatif, fungsi kultural, fungsi komunikasi. Oleh karena itu, meski perubahan terus terjadi, dengan segala pencitraan, dan kemenarikan dunia. Namun apakah yang paling esensi masih bisa didapatkan pada era yang akan terus berkembang dan berubah ini? Dengan segala kecanggihan, kepintaran, kebenaran akankah kebaikan bahkan keindahan serta moral tetap terjaga, terlestarikan? Masyarakat yang masih memegang tradisi seperti di desa maupun sukusuku tertentu terpaksa untuk ikut menjadi bagian dari perkembangan zaman yang semakin canggih dengan berbagai macam teknologinya. Di Eropa, mereka yang sudah semakin canggih dari segala teknologinya telah jenuh dengan segala rutinitas atau hiruk pikuk kesibukan. Mereka mencanangkan Slow City, dalam program kali ini ditekankan pada menjaga dan mempertahankan kondisi budaya lokal dan memajukan kekhasan di dalam kotanya (Widyaningsih, 2008). Hal tersebut sebagian di Indonesia masih dijalankan, dan sebagian besar sudah mulai ditinggalkan. Jika sudah tahu muara akhirnya bakal kembali pada seperti era Eropa saat ini yakni Slow City. Karena telah jenuh dan muak dengan hiruk pikuk dan kesibukan yang tiada henti. Lalu apakah Indonesia masih menghendaki menuju era serba teknologi dan meninggalkan budaya serta bahasa lokalnya.

Masih mungkinkah menggunakan bahasa daerah untuk menjaga karakter generasi selanjutnya? Ketika penutur yang lebih tua dari generasi millenial telah gugur, maka tinggal generasi millenial dan generasi selanjutnya. Apakah masih relevan menggunakan bahasa daerah? Apakah berbahasa daerah akan efektif nantinya? Satu wilayah menjadi sangat heterogen saat ini, apabila tidak kuat penjagaan terhadap ciri khasnya maka semakin luntur pula budayanya, karakternya. Kehilangan arah bukan lagi wacana, melainkan kenyataan. Kita tidak bisa menjaga bahasa daerah secara masif hanya melalui kesadaran pentingnya bahasa daerah sebagai salah satu faktor. Pembentukan karakter di tiap-tiap keluarga juga perlu untuk dikuatkan.

Kita tidak memaksa semua menggunakan bahasa daerah, di luar rumah kebutuhan berkomunikasi tidak cukup diwakilkan satu bahasa saja. Melainkan multibahasa, sehingga kebutuhan akan komunikasi bisa terjalankan dengan baik. Penjaga bahasa daerah yang efektif adalah keluarga, karena sebagian besar keluarga masih dalam satu rumpun yang sama. Realitasnya telah banyak pernikahan beda suku, beda pulau bahkan beda Negara. Pernikahan seperti itu pasti mempertemukan bahasa, budaya dan kebiasaan yang berbeda.

Dari semua hal yang perlu ditekankan adalah pesan atau makna yang terkandung di dalamnya. Makna atau pesan tersebut disampaikan dengan berbagai wujud, bentuk sesuai dengan zamannya. Perwujudan yang disesuaikan dengan minat masyarakat sehingga pesan itu tersampaikan dengan baik. Namun, apa 
bahasa cukup dipahami hanya dengan makna atau isi pesannya saja. Apakah bahasa dasarnya dapat diwakilkan pada bahasa-bahasa lainnya? Apakah ada persamaan kata yang benar-benar dapat mewakilinya? Tentu ada perbedaan, jika memahami dengan bahasa yang berbeda dari bahasa dasarnya. Karena sebenarnya makna tidak hanya didapatkan setelah membaca ringkasan filosofi hidup orang Jawa. Melainkan makna dipelajari melalui proses kehidupan, proses perjalanan sehingga itu yang diwakilkan oleh orang terdahulu dalam kata-kata bijak yang kita kenal saat ini. Oleh karena itu, memahami makna perlu belajar dari yang dasar. Belajar dari dasar itu adalah memakai bahasa tersebut sehari-hari. Ini adalah langkah awal untuk memahami bahasa. Yang terpenting kedua adalah, setelah memahami makna seseorang mampu memberi pemahaman pada orang lain. Seperti dia memberi pemahaman pada anak usia enam tahun. Jika nantinya bahasa daerah tinggal catatan sejarah, maka itu juga tetap penting. Karena mereka yang butuh pasti mencari sampai ke akar. Jika nanti bahasa daerah sudah tak lagi terdengar, tapi tetaplah ada dokumentasinya sehingga generasi selanjutnya dapat belajar dari masa sebelumnya.

Alih-alih berpikir atau cenderung tradisional, tulisan ini sebenarnya berusaha untuk mengambil sisi positif dari segala bidang di sampiang sisi negatif. Kita tetap hidup pada zaman teknologi yang selalu ada pembaharuan hal itu pula menjadi ciri khas atau keunggulan di era sekarang. Namun untuk sisi kemanusiaan, untuk sisi tentang filosofi kehidupan, beberapa hal tradisi yang tersimpan dalam Bahasa Daerah tetap masih dapat menjadi panutan. Oleh karena itu bahasa daerah tetaplah penting untuk dilestarikan.

\section{DAFTAR PUSTAKA}

Amanto, B. S., Umanailo, M. C. B., Wulandari, R. S., Taufik, T., \& Susiati, S. (2019). Local Consumption Diversification. Int. J. Sci. Technol. Res, 8(8), 1865-1869.

Amri, M., Tahir, S. Z. A. B., \& Ahmad, S. (2017). The Implementation of Islamic Teaching in Multiculturalism Society: A Case Study at Pesantren Schools in Indonesia. Asian Social Science, 13(6), 125.

Andini, K. NILAI BUDAYA SUKU BAJO SAMPELA DALAM FILM THE MIRROR NEVER LIES KARYA KAMILA ANDINI.

ARYANA, A. PERBANDINGAN GAYA BAHASA DALAM NOVEL ATHEIS KARYA ACHDIAT KARTA MIHARDJA DAN NOVEL TELEGRAM KARYA PUTU WIJAYA: TINJAUAN STILISTIKA.

Azwan, A. (2018). Politeness strategies of refusals to requests by Ambonese community. LINGUA: Jurnal Bahasa, Sastra, Dan Pengajarannya, 15(1), 1-6.

Bin-Tahir, S. Z., Atmowardoyo, H., Dollah, S., Rinantanti, Y., \& Suriaman, A. (2018). MULTILINGUAL AND MONO-MULTILINGUAL STUDENTS'PERFORMANCE IN ENGLISH SPEAKING. Journal of Advanced English Studies, 1(2), 32-38. 
Bin Tahir, S. Z. (2017). Multilingual teaching and learning at Pesantren Schools in Indonesia. Asian EFL Journal, 89, 74-94.

Bin Tahir, S. Z. (2015). The attitude of Santri and Ustadz toward multilingual education at Pesantren. International Journal of Language and Linguistics, 3(4), 210-216.

Bin-Tahir, S. Z., \& Rinantanti, Y. (2016). Multilingual lecturers' competence in english teaching at the university of Iqra Buru, Indonesia. Asian EFL Journal, 5, 79-92.

Bin-Tahir, S. Z., Saidah, U., Mufidah, N., \& Bugis, R. (2018). The impact of translanguaging approach on teaching Arabic reading in a multilingual classroom. ljaz Arabi Journal of Arabic Learning, 1(1).

Bin-Tahir, S. Z., Bugis, R., \& Tasiana, R. (2017). Intercultural Communication of a Multicultural Family in Buru Regency. Lingual: Journal of Language and Culture, 9(2), 8.

Djamudi, N. L., Nurlaela, M., Nazar, A., Nuryadin, C., Musywirah, I., \& Sari, H. (2019, October). Alternative social environment policy through educational values in Kafi'a's customary speech to the kaledupa community of Wakatobi Island, Indonesia. In IOP Conference Series: Earth and Environmental Science (Vol. 343, No. 1, p. 012118). IOP Publishing.

Djunaidi, F. G., Azwan, A. Y. T., Iye, R., \& bin Tahir, S. Z. Decks Range Gola Village Community Begun District Buton District North.

Indonesia, K. K. D. B. Morfologi Bahasa Indonesia.

Iye, R., \& Susiati, S. (2018). NILAI EDUKATIF DALAM NOVEL SEBAIT CINTA DI BAWAH LANGIT KAIRO KARYA MAHMUD JAUHARI ALI (Educative Values in Sebait Cinta di Bawah Langit Kairo by Mahmud Jauhari Ali). Sirok Bastra, 6(2), 185-191.

lye, R. (2018). Tuturan emosi mahasiswa kota baubau dalam ranah demonstrasi.

Iye, R., Susiati, S., \& Karim, K. (2020). Citra Perempuan dalam Iklan Sabun Shinzui. Sang Pencerah: Jurnal Ilmiah Universitas Muhammadiyah Buton, 6(1), 1-7.

Iye, R. (2018). Tuturan dalam Prosesi Lamaran Pernikahan di Tomia Kabupaten Wakatobi. Jurnal Totobuang, 6(2).

Iye, R. H. NILAI-NILAI MORAL DALAM TOKOH UTAMA PADA NOVEL SATIN MERAH KARYA BRAHMANTO ANINDITO DAN RIE YANTI. TELAGA BAHASA,(7), 2, 195-206.

Iye, R. WRITING SKILLS IN SMP USWATUN HASANAH, BURU DISTRICT.

Iye, R. Jl Prof Dr HAR Basalamah No, and Namlea-Kab Buru.". TUTURAN DALAM PROSESI LAMARAN PERNIKAHAN DI TOMIA KABUPATEN WAKATOBI." Kontemporer. Bandung: PT Remaja.

Karim, K., Maknun, T., \& Abbas, A. (2019). Praanggapan Dalam Pamflet Sosialisasi Pelestarian Lingkungan Di Kabupaten Wakatobi. Jurnal IImu Budaya, 7(2), 241-247. 
Mansyur, F. A., \& Suherman, L. A. (2020). The Function of Proverbs as Educational Media: Anthropological Linguistics on Wolio Proverbs. ELS Journal on Interdisciplinary Studies in Humanities, $3(2), 271-286$.

Rahayaan, I., Azwan, A., \& Bugis, R. (2016). The Students' Writing Ability through Cooperative Script Method. Jurnal Retemena, 2(2).

Sadat, A., Nazar, A., Suherman, L. O. A., Alzarliani, W. O. D., \& Birawida, A. B. (2019, October). Environmental care behavior through e-jas model with science edutainment approach. In IOP Conference Series: Earth and Environmental Science (Vol. 343, No. 1, p. 012126). IOP Publishing.

Sadat, A., Sa'ban, L. M. A., Suherman, L. O. A., Bahari, S., Ibrahim, T., \& Zainal, M. (2019, October). Internalization characters of environmental care and disaster response through care partner schools. In IOP Conference Series: Earth and Environmental Science (Vol. 343, No. 1, p. 012125). IOP Publishing.

Salamun, T. (2018). DEIKSIS PERSONA BAHASA INDONESIA DIALEK AMBON [Personal Deixes of Indonesian Leanguage With Ambonese Dialect]. Totobuang, 5, 325-339.

Salamun, T. (2018). RELASI KEKERABATAN BAHASA HITU, WAKAL, MORELA, MAMALA, DAN HILA DI PROVINSI MALUKU [The Family Relationship Language Hitu, Wakal, Morela, Mamala, and Hila in Maluku Province].

Suherman, L. A. (2018). The Analysis of Metaphorical Domain on English "Stab Verb" in Corpora. ELS Journal on Interdisciplinary Studies in Humanities, 1(1), 52-58.

Suherman, L. O. A., Salam, S., Mursanto, D., Efendi, A., Bahar, S. B., \& Kanna, T. (2019, October). The effect of open-air curing on compressive strength of geopolymer mortar containing laterite soil and slaked lime. In IOP Conference Series: Earth and Environmental Science (Vol. 343, No. 1, p. 012133). IOP Publishing.

Susiati, S., \& Iye, R. (2018). Kajian Geografi Bahasa dan Dialek di Sulawesi Tenggara: Analisis Dialektometri. Gramatika: Jurnal IImiah Kebahasaan dan Kesastraan, 6(2), 137-151.

Susiati, S., Iye, R., \& Suherman, L. O. A. (2019). Hot Potatoes Multimedia Applications in Evaluation of Indonesian Learning In SMP Students in Buru District. ELS Journal on Interdisciplinary Studies in Humanities, 2(4), 556-570.

Susiati, S. (2018). Homonim bahasa kepulauan tukang besi dialek kaledupa di kabupaten wakatobi [the homonymon of tukang besi island languange in kaledupa dialect at wakatobi regency]. Totobuang, 6 (1), 109, 123.

Susiati, S. (2020). Emosi Verbal Suku Bajo Sampela.

Susiati, S. (2020). Fenomena Tuturan Emosi Verbal Bahasa Indonesia Suku Bajo Sampela.

Susiati, S. (2020). Nilai Budaya Suku Bajo Sampela Dalam Film The Mirror Never Lies Karya Kamila Andini. 
Susiati, S. (2020). Konsep Pertentangan Dalam Film" Aisyah Biarkan Kami Bersaudara" Karya Herwin Novianto.

Susiati, S. (2020). Strategi AMBT untuk Meningkatkan Kemampuan Membaca Pemahaman Interpretatif Siswa Kelas IV SD Negeri 3 Namlea Kabupaten Buru.

Susiati, S. (2020). Fungsi Konatif Pada Iklan Mesin Cuci Hole-Less Tub Dari Sharp: Analisis Wacana Kritis.

Susiati, S. (2020). GAYA BAHASA SECARA UMUM DAN GAYA BAHASA PEMBUNGKUS PIKIRAN.

Susiati, S. (2020). The Concept Of Togetherness In The Films" Aisyah Biarkan Kami Bersaudara" By Herwin Novianto.

Susiati, S. (2020). Konsep Kebersamaan Dalam Film" Aisyah Biarkan Kami Bersaudara" Karya Herwin Novianto.

Susiati, S. (2020). Teori dan Aliran Linguistik: Tata Bahasa Generatif.

Susiati, S. (2020). Metode Pembelajaran Bahasa Indonesia: Sosiodrama.

Susiati, S. (2020). Rekontruksi Internal Bahasa Bugis dan Bahasa Makassar: Linguistik Komparatif.

Susiati, S. Bahan Ajar: Psikolinguistik.

Susiati, S. (2020). PENTINGNYA MELESTARIKAN BAHASA DAERAH.

Susiati, S. (2020). Morfologi Kelas Kata Dalam Bahasa Indonesia.

Susiati, S. (2020). Semantik: Teori Semantik, Relasi Makna, Marked, Dan Unmarked.

Susiati, Y. T. Risman Iye. A. Kesantunan Imperatif Bahasa Indonesia Suku Bajo Sampela: Balai Pembinaan dan Pengembangan Bahasa. 2018. Kongres Bahasa Indonesia (No. 12, pp. 1-6). Report.

Susiati, S. (2020). Kesantunan Imperatif Bahasa Melayu Ambon.

Susiati, S. (2020). Gaya Bahasa Secara Umum Dan Gaya Bahasa Pembungkus Pikiran: Stilistika.

Susiati, S. (2020). Tuturan Kesantunan Imperatif Bahasa Indonesia Suku Bajo Sampela.

Susiati, S. (2020). Nilai Budaya Suku Bajo Sampela Dalam Film The Mirror Never Lies Karya Kamila Andini.

Susiati, S. (2020). Pengaplikasian Multimedia Hot Potatoes Dalam Evaluasi Pembelajaran Bahasa Indonesia Pada Siswa SMP Negeri 9 Buru.

Susiati, S., \& lye, R. (2018). Kajian Geografi Bahasa dan Dialek di Sulawesi Tenggara: Analisis Dialektometri. Gramatika: Jurnal IImiah Kebahasaan dan Kesastraan. 6 (2), 137-151.

Susiati, S. (2020). Kaidah Fonologi Bahasa Indonesia. 
Susiati, S. (2020). Wujud Morfologi Bahasa Indonesia.

Susiati, S. (2020). Makian Bahasa Wakatobi Dialek Kaledupa.

Susiati, S. (2020). Eksistensi Manusia Dalam Film" Aisyah Biarkan Kami Bersaudara" Karya Herwin Novianto.

Susiati, S. NILAI BUDAYA SUKU BAJO SAMPELA DALAM FILM THE MIRROR NEVER LIES.

Susiati, S. (2020). Konsep Keterasingan Dalam Film" Aisyah Biarkan Kami Bersaudara" Karya Herwin Novianto.

Susiati, S. (2020). Concept Of Conflict In The Films "AISYAH BIARKAN KAMI BERSAUDARA" By Herwin Novianto.

Susiati, S. (2020). Embrio Nasionalisme Dalam Bahasa dan Sastra.

Susiati, S. PERWUJUDAN SIMILE OLEH MERARI SIREGAR DALAM NOVEL AZAB DAN SENGSARA.

Susiati, S. (2020). Nilai Pembentuk Karakter Masyarakat Wakatobi Melalui Kabhanti Wa Leja.

Tahir, S. Z. A. B. (2017). Pengembangan Materi Multibahasa untuk Siswa Pesantren. Unpublish dissertation.

Tahir, S. Z. B. (2015). Multilingual Teaching And Learning At Pesantren. 14 Asian EFL Journal Conference.

Tenriawali, A. Y. (2018). Representasi korban kekerasan dalam teks berita daring tribun timur: analisis wacana kritis [the representation victims of violence in tribun timur online news text: critical discourse analysis]. TOTOBUANG, 6 (1), 1, 15.

Yusdianti, A. (2020). THE REPRESENTATION VICTIMS OF VIOLENCE IN TRIBUN TIMUR ONLINE NEWS TEXT: CRITICAL DISCOURSE ANALYSIS. 